\title{
DEFICIÊNCIA E SEXUALIDADE: UMA ANÁLISE BIBLIOMÉTRICA
}

\author{
DISCAPACIDAD Y SEXUALIDAD: UN ANÁLISIS BIBLIOMÉTRICO
}

DISABILITY AND SEXUALITY: A BIBLIOMETRIC ANALYSIS

\author{
Marlon Jose Gavlik MENDES ${ }^{1}$ \\ Fátima Elisabeth DENARI ${ }^{2}$
}

\begin{abstract}
RESUMO: A vivência da sexualidade pelas pessoas com deficiência é um assunto que desperta interesse de pesquisadores e profissionais da educação especial. Esta pesquisa teve por objetivo investigar os artigos científicos que abordam a vivência da sexualidade pelas pessoas com deficiência. Foi realizado um estudo bibliométrico sobre a produção científica brasileira na temática. Do total de 20 artigos analisados, a maioria contém pesquisas qualitativas, descritivas e com entrevistas como instrumento de coleta de dados. Os públicos mais investigados foram os educadores de alunos com deficiência e as pessoas com deficiência física. Os resultados demonstram grandes discrepâncias entre as representações de ambos os grupos, prevalecendo o preconceito e a desinformação. Ainda há muitos temas a serem abordados em futuras pesquisas, sendo sugerido a realização de novos estudos e a construção de programas de educação sexual para alunos com deficiência.
\end{abstract}

PALAVRAS-CHAVE: Educação especial. Pessoa com deficiência. Sexualidade. Educação sexual. Bibliometria.

RESUMEN: La vivencia de la sexualidad por las personas con discapacidad es un tema que despierta el interés en investigadores y profesionales de la educación especial. Esta pesquisa tuvo por objetivo investigar los artículos científicos que tratan de la vivencia de la sexualidad por las personas con discapacidad. Se realizó un estudio bibliométrico sobre la producción científica brasileña en la temática. Del total de 20 artículos analizados, la mayoría contiene pesquisas cualitativas, descriptivas y con entrevistas como instrumento de recolección de datos. El público más investigado fueron los educadores de estu3diantes con discapacidad y personas con discapacidad física, con grandes diferencias entre las representaciones de ambos los grupos sobre la sexualidad de personas con discapacidad, con la predominancia del prejuicio y desinformación. Todavía hay muchos temas a abordar en futuras investigaciones, siendo interesante la realización de nuevos estudios y la construcción de programas de educación sexual para estudiantes con discapacidad.

PALABRAS CLAVE: Educación especial. Persona con discapacidad. Sexualidad. Educación sexual. Bibliometría.

\footnotetext{
${ }^{1}$ Universidade Federal de São Carlos (UFSCAR), São Carlos - SP - Brasil. Doutorando pelo Programa de PósGraduação em Educação Especial do Departamento de Psicologia. ORCID: <http://orcid.org/0000-0002-3473610X>. E-mail: mgmgavlik@ hotmail.com

${ }^{2}$ Universidade Federal de São Carlos (UFSCAR), São Carlos - SP - Brasil. Professora titular do Departamento de Psicologia. ORCID: <http://orcid.org/0000-0001-9248-6359>. E-mail: fadenari@terra.com.br
} 
ABSTRACT: The experience of sexuality by people with some disability is an phenomenon that attracts interest from researchers and professionals in special education. This research had the objetive to investigate the scientific articles that address the experience of sexuality by people with disabilities. A bibliometric study was carried out on brazilian's scientific production on the subject. Of the total of 20 articles analyzed, most of then contain qualitative and descriptive reseaches with interviews as a data collection instrument. The most investigated public were educators of students with disabilities and people with physical disability, with large discrepancies between the representations of both groups about the sexuality of people with disabilities, prevailing prejudice and misinformation. There are still many issues to be addressed in futures researches, as well as new studies and the construction of sex education programs for students with disabilities.

KEYWORDS: Special education. Disabled persons. Sexuality. Sex education. Bibliometry.

\section{Introdução}

A produção cientifica em educação especial é perpassada por variadas temáticas. A escolaridade, as relações sociais e familiares de pessoas com deficiência (PcD) despertam interesse de pesquisadores e pesquisadoras nacionais e internacionais. Dentre as temáticas envolvendo as $\mathrm{PcD}$, uma das que gera mais curiosidade é o desenvolvimento sexual e afetivo das pessoas com deficiência.

Segundo a Lei Brasileira de Inclusão da Pessoa com Deficiência, também conhecida como o Estatuto da Pessoa com Deficiência, identifica-se como PcD quem possui impedimentos físicos, mentais, intelectuais ou sensoriais, tanto de origem congênita quanto adquiridos ao longo da vida, sendo que esses impedimentos podem comprometer a participação plena dessas pessoas na sociedade. São tipos de deficiência: a deficiência física, intelectual, mental, sensorial, a qual se divide em visual e auditiva, e múltipla (BRASIL, 2015).

Historicamente, segundo Amaral (1998), as pessoas com deficiência foram colocadas à margem da sociedade, sendo atendidas por instituições especificas, podendo ser privadas do convívio comunitário. Esse grupo foi pouco a pouco conquistando maiores espaços na sociedade, mas esse processo foi e ainda é complexo. Mesmo na atualidade, como relatam Mazzotta e D'antino (2011), a pessoa com deficiência pode encontrar barreiras, assim como se deparar com preconceitos das demais pessoas ao conviver em sua comunidade, frequentar a escola e o local de trabalho, assim como quando vive sua sexualidade.

Entende-se por sexualidade, a partir de Foucault (1976), o uso do corpo e de seus prazeres. A sexualidade, assim, é um fenômeno inerente a todos os seres humanos, não se limitando ao coito ou às práticas genitais, mas sim, englobando processos corporais e afetivos. 
Mesmo a sexualidade se fazendo presente na vida de todas as pessoas, esta é alvo de controle social por diversas instituições, como a igreja, o governo e a escola.

A sexualidade de corpos considerados divergentes, como as PcD, é alvo de maior controle social. O sexo e os corpos valorizados pela mídia e ensinados nas escolas englobam apenas aqueles considerados "normais", saudáveis e não possuidores de deficiências, o que contribui para fomentar e perpetuar os diversos mitos que circundam a sexualidade das pessoas com deficiência (LEITE JÚNIOR, 2006).

De acordo com Gesser e Nuernberg (2014), exemplos de mitos que circundam a sexualidade desse grupo são as concepções de pessoas com deficiência como sendo seres assexuados ou com uma sexualidade descontrolada. O mito da assexualidade pode vir acompanhado de infantilização, enquanto o mito do descontrole sexual muitas vezes se relaciona com ideias de selvageria, caracterizando-se pela noção errônea de que as PcD são incapazes de relacionamentos afetivos maduros. O mito oposto também é visível, sendo a ideia de que quem possui deficiência, principalmente intelectual, tem a expressão da sexualidade exacerbada, mas não é capaz de relações sexuais genitais (GIAMI, 2004). Há também o mito de que as PcD apenas geram outras crianças com deficiência, contribuindo para o isolamento dessa população e para que tenham seus direitos sexuais e reprodutivos negados.

Os mitos e ideias preconceituosas, como afirmam Gomes et al. (2017), se fazem presentes na vivência da sexualidade das pessoas com deficiência. O preconceito direcionado a essas pessoas se relaciona à ideia de normalidade, de sexo útil, correto e não pecaminoso, o que põe em detrimento quem não corresponde aos padrões de corpos e comportamentos "normais" divulgados pelas diversas instituições. Muitas vezes esses preconceitos estão enraizados, dificultando a vivência da sexualidade a partir da visão de outros, tanto pela ideia de inadequação ou pela ideia de inexistência de sexualidade, apenas falando sobre a sexualidade quando começa a se manifestar de modo inadequado, como um "problema" (SIMÕES, 2017).

$\mathrm{Na}$ atualidade, as pesquisas que aproximam as temáticas da sexualidade e da deficiência demonstram tendências na discussão da construção do corpo e das noções de beleza, apontando que, em um mundo no qual a vivência da sexualidade e do erotismo depende de atributos físicos considerados belos, as pessoas com deficiência têm sua vida afetiva e sexual afetadas por não se encaixar nos padrões físicos de beleza corporal (OLIVEIRA et al., 2017). A funcionalidade do corpo também influencia na vivência da sexualidade, como discutiu Silva et al. (2015), tendo pessoas que, por possuir um corpo deficiente e não correspondente às normas de funcionalidade, se sentem desencorajadas a viver sua sexualidade. 
As pesquisas científicas que discutem a sexualidade das PcD são necessárias para desmistificar os mitos que circunscrevem a temática, promovendo melhor relação com a sexualidade humana e questionando as regras e ideias pré-estabelecidas direcionados às noções de corpo, sexo, funcionalidade e deficiência. Devido a essas problemáticas, a pergunta que norteou nossa pesquisa foi: como é retratada a sexualidade das pessoas com deficiência na produção científica brasileira? O objetivo da pesquisa foi investigar os artigos científicos que abordam essa temática e de que forma a expressam.

\section{Método}

A pesquisa realizada teve caráter descritivo, utilizando a análise bibliométrica. A bibliometria, para Hayashi (2013), é um método de análise do campo de conhecimento científico que pretende investigar a produção e a produtividade de determinada área da ciência, podendo servir para indicar temas trabalhados, lacunas existentes da produção acadêmica e redes de colaboração entre autores e instituições, construindo um mapeamento de determinado campo científico.

Como escrevem Ruas e Pereira (2014),

[...] o objetivo das análises bibliométricas [...] é mensurar o processo de transformação e aplicação do conhecimento. A partir do seu entendimento é possível identificar redes nacionais e internacionais de colaboração, mapear a evolução de novos campos da ciência e da tecnologia, bem como conhecer a lógica interna de desenvolvimento da ciência (RUAS; PEREIRA, 2014, p. 56).

Para se realizar uma análise bibliométrica, é necessário utilizar-se de noções quantitativas e estatísticas para descrever um campo ou área da produção científica. A análise é realizada a partir da eleição de indicadores bibliométricos, que são os aspectos da produção que serão analisados e descritos quantitativamente e qualitativamente. Exemplo de indicadores podem ser o ano, autores, palavras que se repetem nos artigos, entre outros.

Nessa pesquisa foi realizada uma análise bibliométrica em artigos científicos que discutiram as concepções da sexualidade de pessoas com deficiência. O material analisado é proveniente de uma busca realizada no portal de periódicos da Coordenação de Aperfeiçoamento de Pessoal de Nível Superior (CAPES) ${ }^{3}$. Foi utilizada a combinação de descritores: Deficiência AND Sexualidade, sendo que o artigo deveria possuir esses termos

${ }_{3}^{3}$ Disponível em: http://www-periodicos-capes-gov-br.ez31.periodicos.capes.gov.br/ Acesso em: 04 Jul. 2018.

RIAEE - Revista Ibero-Americana de Estudos em Educação, Araraquara, v. 14, n. esp. 2, p. 1357-1354, jul., 2019. E-ISSN: $1982-5587$. 
seus títulos ou palavras-chave ${ }^{4}$. $\mathrm{O}$ ano da publicação não foi delimitado. Após a busca inicial, foram aplicados os critérios de inclusão, que foram: artigos; escritos em língua portuguesa ou inglesa; que discutam a sexualidade de pessoas com deficiência tanto teoricamente quanto a partir de pesquisas de campo.

Ao fim das buscas e da aplicação dos critérios de inclusão foram encontrados 21 artigos disponíveis pelo portal de periódicos da CAPES, distribuídos entre os anos de 2002 e 2018 . Desse total de artigos, um encontrava-se repetido, então a amostra analisada contou com 20 artigos.

\section{Resultados e discussão}

Do total de artigos analisados, as revistas que contaram com mais publicações foram a Revista Ibero-Americana de Estudos em Educação, com três artigos, a Revista Brasileira de Educação Especial, também com três artigos, e as revistas Interação em Psicologia e Ciência \& Saúde Coletiva, ambas com dois artigos cada.

Analisando as publicações por ano, é notável maior incidência de artigos nos anos de 2005 e 2010, com dois artigos em cada ano, e em 2012 e 2015, com três artigos em cada ano. A distribuição de publicações por ano pode ser conferida no gráfico a seguir:

Figura 1 - Gráfico de distribuição dos artigos por ano

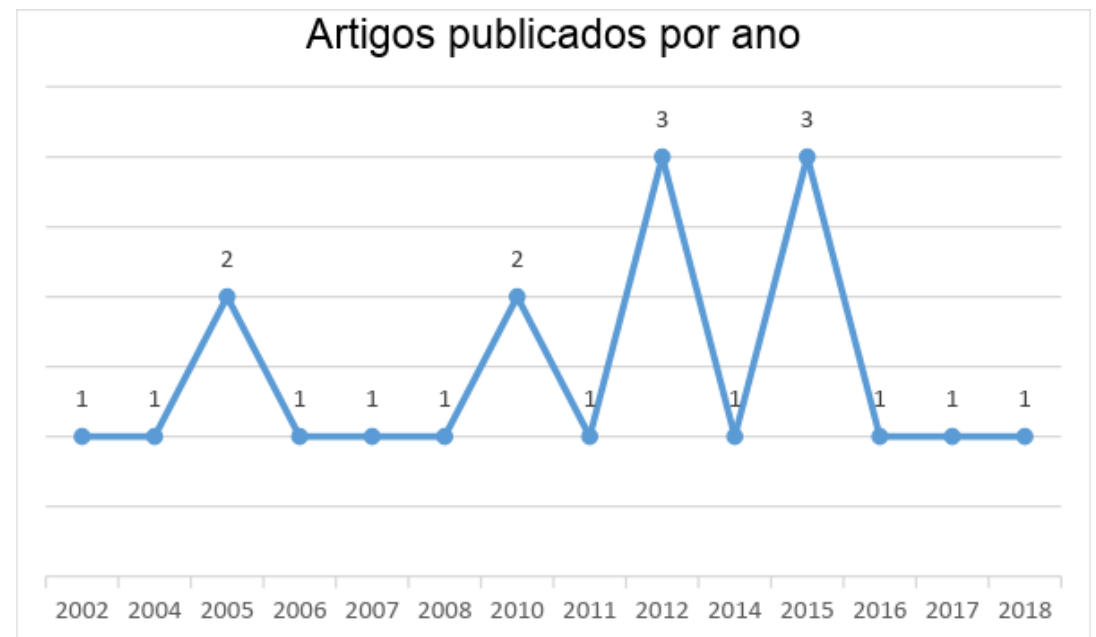

Fonte: Autoria própria.

O artigo mais antigo encontrado foi do ano de 2002, sendo observada uma produção constante até os anos mais recentes. As últimas décadas foram marcadas por diversos avanços

${ }^{4}$ Busca realizada em Julho de 2018.

RIAEE - Revista Ibero-Americana de Estudos em Educação, Araraquara, v. 14, n. esp. 2, p. 1357-1354, jul., 2019. E-ISSN: 1982-5587. 
legais envolvendo os estudos e a escolaridade de pessoas com deficiência. A Política Nacional de Educação Especial na perspectiva da educação inclusiva de 2008 foi um grande marco para a escolaridade das $\mathrm{PcD}$, motivando vários estudos envolvendo as pessoas com deficiência, como observa-se no aumento de pesquisa nos anos que seguiram a legislação. Outro marco significativo foi a Lei Brasileira de Inclusão, também conhecida como o Estatuto da Pessoa com Deficiência, de 2015, a qual reforçou os direitos sociais, afetivos e reprodutivos desse público, também podendo ter motivado o fluxo de pesquisas observadas até os dias atuais.

A distribuição dos artigos pela instituição de origem dos autores e coautores pode ser observada no quadro a seguir:

Figura 2 - Quadro de distribuição dos autores e coautores por instituição de origem

\begin{tabular}{|cc|}
\hline Instituição de ensino superior & $\begin{array}{c}\text { Quantidade de autores e coautores } \\
\text { vinculados }\end{array}$ \\
\hline Instituto Universitário de Lisboa & 1 \\
Escola Superior de Educação Paula Frassinetti. & 1 \\
Universidade Federal do Piauí & 1 \\
Universidade Federal do Ceará & 1 \\
Universidade Federal de Uberlândia & 1 \\
Universidade Federal de Pelotas & 1 \\
Universidade Federal de Santa Catarina & 2 \\
Universidade Federal de São Carlos & 3 \\
Universidade Federal da Paraíba & 3 \\
Universidade de São Paulo & 3 \\
Universidade de Aveiro & 4 \\
Centro Universitário Vila Velha & 4 \\
Instituto Fernandes Figueira & 7 \\
Filho & 11 \\
Universidade Estadual Paulista Júlio de Mesquita & \\
& \\
\hline
\end{tabular}

Fonte: Autoria própria.

Mesmo tendo mais de um artigo escrito pelos mesmos autores, com esse indicador bibliométrico nota-se a maior incidência de estudos publicados por pesquisadores da 
Universidade Estadual Paulista Júlio de Mesquita Filho, do estado de São Paulo, e do Instituto Fernandes Figueira, do estado do Rio de Janeiro.

A Universidade Estadual Paulista Júlio de Mesquita Filho/UNESP, em específico o campus de Araraquara, no estado de São Paulo, conta com o único programa de pós-graduação stricto-sensu em educação sexual ${ }^{5}$ do Brasil. O programa faz parte da Faculdade de Ciências e Letras do campus de Araraquara e conta com diversos pesquisadores de variadas áreas do conhecimento. Atualmente o programa oferece formação de mestrado na modalidade de mestrado profissional, recebendo nota 4 na última avaliação da CAPES.

Adentrando mais nos textos analisados, percebe-se que as palavras-chave mais utilizadas nos artigos dizem respeito às deficiências físicas e intelectuais, à educação sexual e à juventude, enquanto os termos que versam sobre o abuso sexual e a orientação sexual são os que menos foram utilizados, como pode ser observado no gráfico a seguir:

Figura 3 - Gráfico de palavras-chave utilizadas nos artigos

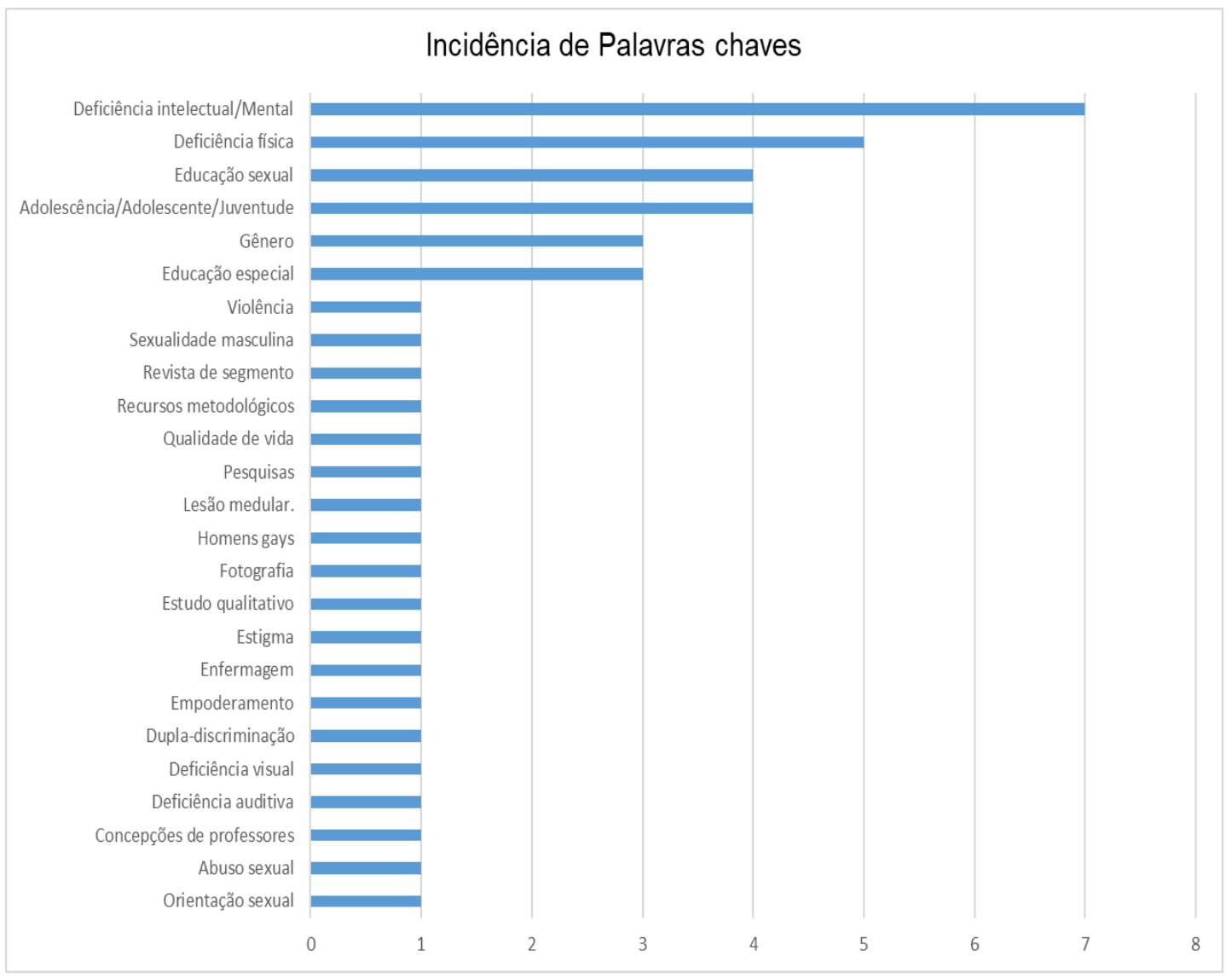

Fonte: Autoria própria.

${ }^{5}$ Site do Programa: https://www.fclar.unesp.br/\#!/pos-graduacao/stricto-sensu/educacao-sexual/ 
Foram excluídas da análise das palavras-chave os termos "sexualidade" e "deficiência", visto que a incidência desses termos foi requisito na inclusão dos artigos analisados. A análise das palavras-chave já dá indícios das temáticas abordadas pelos artigos. Temáticas como a educação e a juventude se destacam na análise textual dos resumos e palavras-chave, assim como o interesse em discutir a sexualidade de pessoas com deficiência física (DF) e deficiência intelectual (DI). Investigando as pesquisas descritas nos artigos, foi encontrada maior concentração de estudos qualitativos, como observa-se na Figura 4:

Figura 4 - Gráfico de pesquisas qualitativas e quali-quantitativas

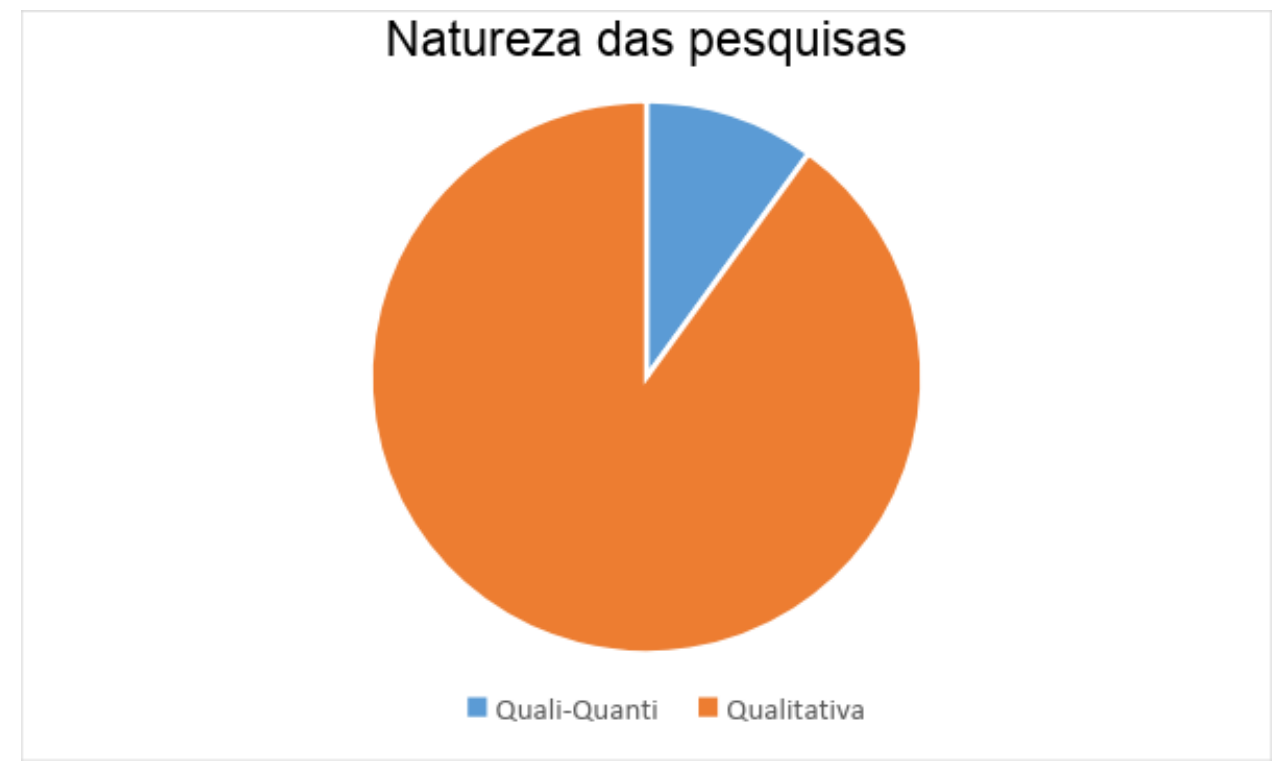

Fonte: Autoria própria.

Nesse indicador bibliométrico há um total de 18 pesquisas realizadas com um delineamento qualitativo, enquanto apenas 2 trabalharam seus dados de maneira quantiqualitativas. A pesquisa qualitativa ainda é uma modalidade de estudo que desperta grande interesse de pesquisadores, tendo diversas potencialidades e cuidados éticos a serem tomados, como a atenção do pesquisador na avaliação da relevância de sua pesquisa e a análise dos dados coletados. A pesquisa qualitativa também tem grande incidência nas áreas da educação e da educação especial, devido à flexibilidade das temáticas trabalhadas e ao contato direto com o público investigado. (AMADO, 2017)

Os objetivos dos artigos foram os mais diversos possíveis. As temáticas centrais podem ser conferidas na tabela a seguir: 
Figura 5 - Tabela de objetivos das pesquisas analisadas

\begin{tabular}{|c|c|}
\hline Objetivos & $\begin{array}{l}\text { Número de } \\
\text { estudos }\end{array}$ \\
\hline $\begin{array}{l}\text { Discutir como a sexualidade das pessoas com deficiência é retratada } \\
\text { em revistas e livros }\end{array}$ & 2 \\
\hline $\begin{array}{l}\text { Obter e discutir relatos e representações das pessoas com deficiências } \\
\text { sobre sua própria sexualidade }\end{array}$ & 9 \\
\hline $\begin{array}{l}\text { Descrever e aplicar programas de intervenção em educação e } \\
\text { orientação sexual para pessoas com deficiência }\end{array}$ & 2 \\
\hline $\begin{array}{l}\text { Investigar a discriminação relacionada a deficiências e questões de } \\
\text { sexualidade e orientação sexual. }\end{array}$ & 1 \\
\hline $\begin{array}{l}\text { Investigar as representações de pais, mães e responsáveis de crianças } \\
\text { e jovens com deficiência sobre a sexualidade de seus filhos }\end{array}$ & 2 \\
\hline $\begin{array}{c}\text { Investigar a produção cientifica sobre a sexualidade de pessoas com } \\
\text { deficiência }\end{array}$ & 3 \\
\hline $\begin{array}{c}\text { Investigar as representações de professores, educadores e } \\
\text { profissionais de alunos com deficiência sobre a sexualidade de seus } \\
\text { estudantes. }\end{array}$ & 2 \\
\hline
\end{tabular}

Fonte: Autoria própria.

Os objetivos demonstrados pela tabela excedem o total dos 20 artigos analisados, visto que um estudo teve como objetivo investigar tanto as representações de professores e profissionais quanto de pessoas com deficiência, concomitantemente, encaixando-se em ambas as categorias de objetivos. O objetivo de pesquisa que mais se fez presente nos estudos foi investigar as representações da pessoa com deficiência sobre a própria sexualidade. Também é interessante ressaltar o interesse visível em compreender as concepções de pais, mães e responsáveis, além de professores, professoras e educadores a respeito da sexualidade das $\mathrm{PcD}$.

As concepções, ideias e representações de algum fenômeno despertam interesses de variados pesquisadores. Investigar as representações envolve entrar em contato com processos subjetivos de uma pessoa ou grupo, ao mesmo tempo que também se manifestam os processos sociais e culturais que influenciam na mentalidade individual. A mesma tendência metodológica também é observada em pesquisas sobre a sexualidade com outros públicos, como os idosos (VIEIRA et al., 2016), universitários (CARLOS et al., 2018) e professores atuantes da rede básica de ensino (MIRANDA, 2014).

Sobre o tipo de pesquisa e os métodos utilizados para atingir seus objetivos, muitos pesquisadores utilizaram de pesquisas descritivas, como é possível conferir: 
Figura 6 - Gráfico de tipos de pesquisas

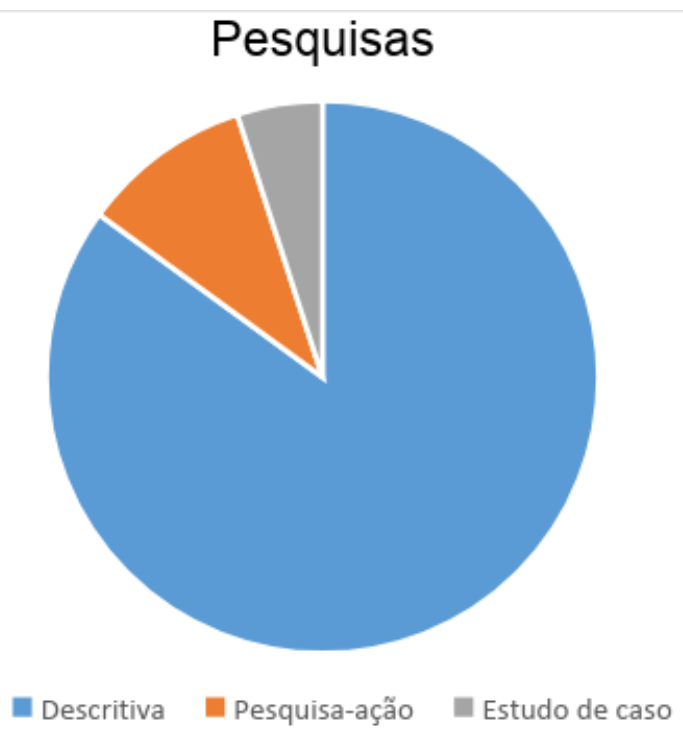

Fonte: Autoria própria.

Observa-se duas pesquisas-ação sendo realizadas e apenas um estudo de caso. Como método para a coleta de dados, o instrumento mais utilizado foram as entrevistas, tanto semiestruturadas quanto de tipos não explicitados nos artigos:

Figura 7 - Gráfico de métodos de coleta de dados utilizados nas pesquisas Métodos de coleta de dados

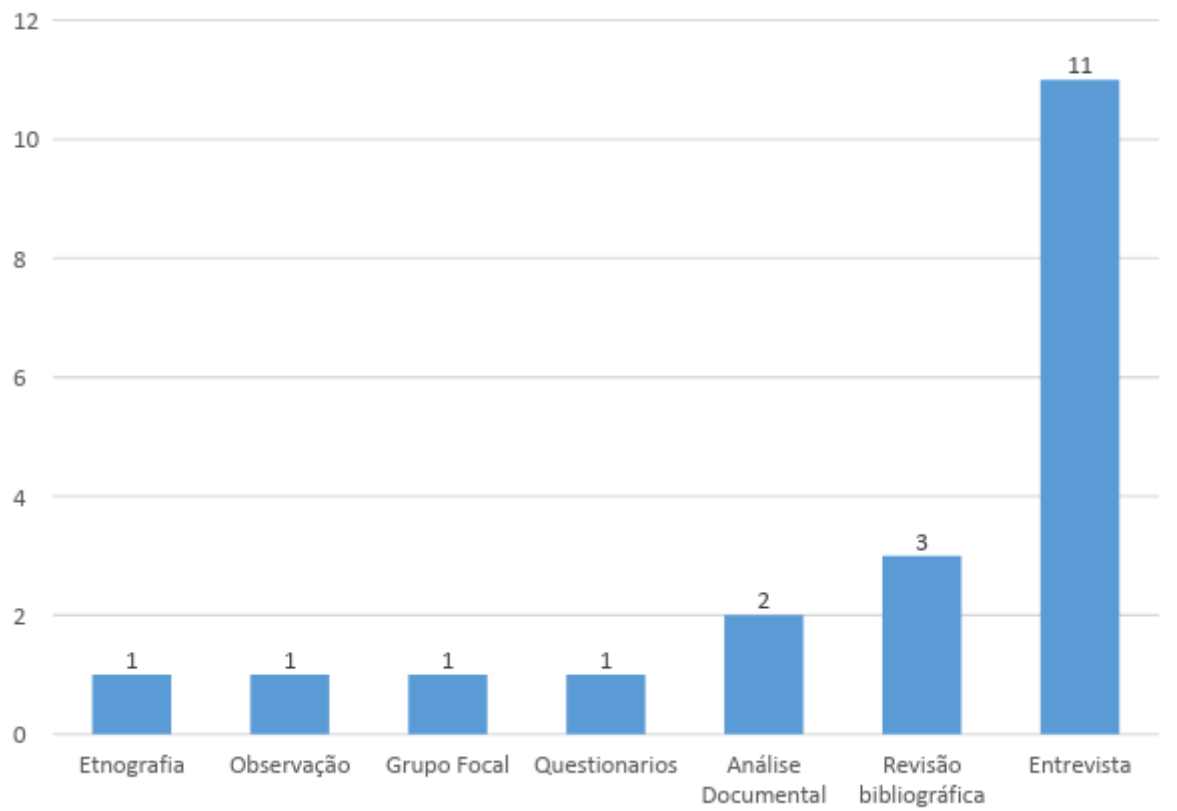

Fonte: Autoria própria. 
Ressalta-se que muitos estudos não explicitavam que estilo de entrevista foi utilizado; alguns deixaram claro que se utilizou de um roteiro semiestruturado e um artigo utilizou de uma entrevista com imagens para coletar dados com adolescentes com deficiência intelectual.

Sobre o público abordado nas pesquisas, há maior incidência de investigações sobre a sexualidade de pessoas com deficiência intelectual e física, como é possível notar:

Figura 8 - Gráfico do público abordado nos artigos

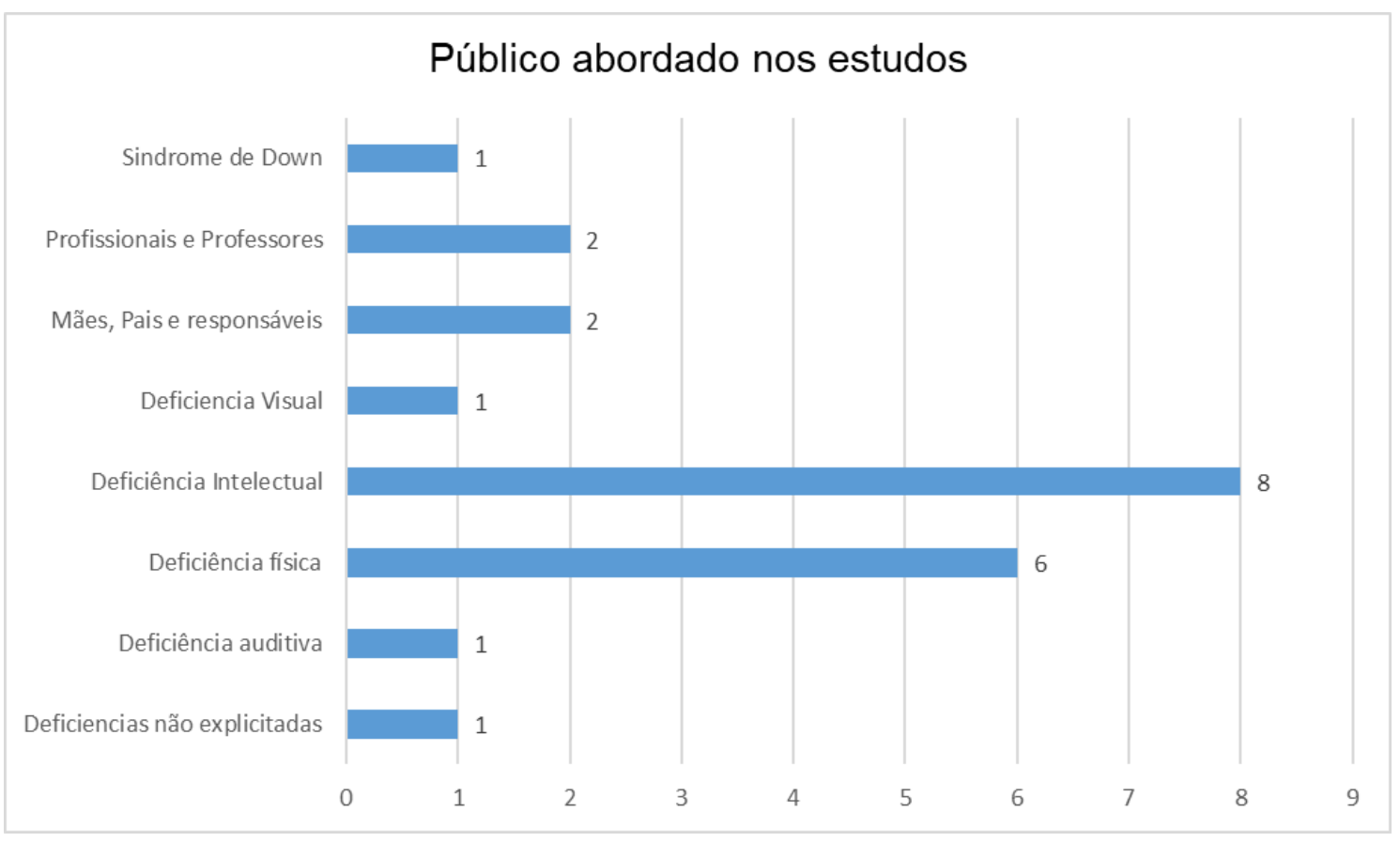

Fonte: Autoria própria.

O público mais abordado na pesquisa, como também ficou evidente na análise das palavras-chave na figura 3, são as pessoas com deficiência intelectual e física. Historicamente, as pessoas com anormalidades corporais visíveis são alvo de maior atenção de outras pessoas, tanto em caso de adoração quanto em ofensas, exclusões e violências (GOFFMAN, 1988). No que tange às deficiências, o mesmo fenômeno ocorre com pessoas que possuem deficiências visíveis em um primeiro contato social, como a deficiência física. Esse público vem a despertar, assim, maior interesse de pesquisadores em estudos (AMARAL, 1994), como é observado nas pesquisas que investigaram sobre sexualidade. Ao contrário, é possível notar poucas discussões envolvendo pessoas com deficiência visual e auditiva, sendo um público interessante para envolver em futuras pesquisas.

Quantificando os participantes das pesquisas que envolveram seres humanos, observase os seguintes resultados: 
Figura 9 - Gráfico do número de participantes das pesquisas

\section{Número de participantes das pesquisas}

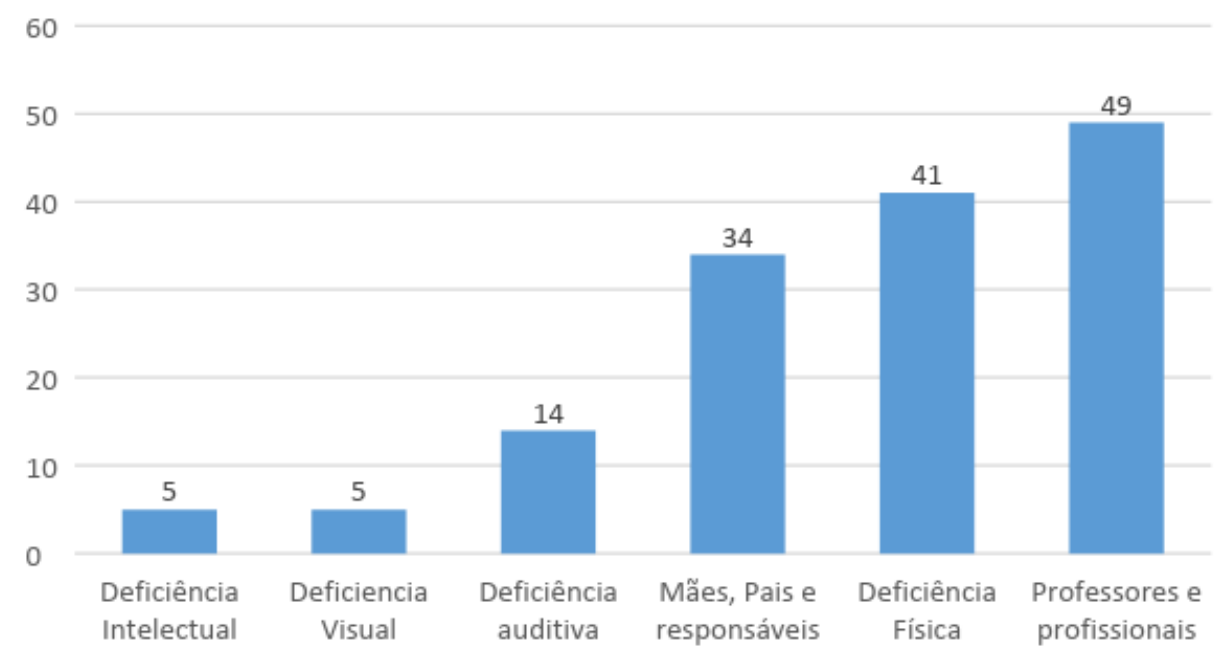

Fonte: Autoria própria.

Houve maior número de professores/as, profissionais e pais, mães e responsáveis entrevistados, e muitas dessas pessoas estavam vinculadas a alunos/as ou filhos/as com deficiência intelectual. Dentro das $\mathrm{PcD}$, as pessoas com deficiência física, em sua maioria pessoas paraplégicas, foram as mais convidadas a fornecer seus relatos. Poucas pessoas com deficiência intelectual foram chamadas a relatar suas experiências, sendo ouvido mais de seus responsáveis e educadores. Esse dado entra em conflito com os indicadores demonstrados nas figuras 5 e 8 . Se, por um lado, há grande interesse em investigar a vivência da sexualidade das pessoas com deficiência a partir de seus próprios relatos, por outro lado, quem fala mais sobre o fenômeno, principalmente no caso da deficiência intelectual, não são elas, e sim seus educadores e responsáveis.

Esse fenômeno, como afirma Maffesoli (2002), é histórico e vem se repetindo ao longo da cultura humana: grupos não sendo legitimados em sua voz e seu poder de intervenção social e tendo outros grupos falando por eles, ditando suas demandas e necessidades. Observa-se esse fenômeno nos artigos analisados; por mais que algumas pessoas com deficiência intelectual tenham sido ouvidas, a sua sexualidade ainda é relatada a partir de terceiros.

A deficiência intelectual (DI), historicamente, é uma condição que é associada a ideias de incapacidade, invisibilidade e desvio frente às exigências da sociedade capitalista. Pessoas com DI frequentemente vivem sob a tutela de familiares ou de instituições, sendo esses responsáveis quem cuidam de suas necessidades e mediam sua convivência com o mundo, muitas vezes "falando" por elas, isto é, decidindo desde as situações mais simples e comuns 
do dia a dia, até aquelas que dizem respeito à expressão de sua afetividade e vivências sexuais (DENARI, 2010).

Analisando os resultados das pesquisas, os artigos que realizaram revisões bibliográficas na literatura a respeito da vivência da sexualidade das PcD demonstram que os jovens com deficiência intelectual são privados de conhecimentos sobre a sexualidade humana, muitas vezes por seus responsáveis e educadores. E o receio de pais e mães pode ser proveniente de preconceitos a respeito da sexualidade, o que dificulta até discussões envolvendo o abuso sexual e a gravidez, impossibilitando uma educação sexual, tanto partindo dos responsáveis quanto dos educadores.

As pesquisas que investigaram as concepções de mães, pais e responsáveis sobre o desenvolvimento sexual de seus filhos com deficiência intelectual demonstram que muitos pais e mães vêm seus filhos de maneira infantilizada e superprotetora, entendendo as pessoas com deficiência como não tendo uma sexualidade. Se fazem presentes os mitos envolvendo a sexualidade das $\mathrm{PcD}$, em grande parte o mito da assexualidade desse grupo (GESSER; NUERNBERG, 2014). A maioria dos familiares não orienta os filhos sexualmente, e quando se orienta os assuntos mais tratados dizem respeito a mudanças corporais e ao abuso sexual.

No que tange às concepções de professoras, professores, educadores e profissionais, os profissionais que trabalham em instituições de educação especial carregam receio frente às manifestações da sexualidade de seus alunos com deficiência intelectual, entendendo-as como descontroladas e até perigosas. No caso de professores e professoras do ensino regular e do atendimento educacional especializado, muitos comportamentos de seus alunos causam espanto e receio nos educadores, mas esses comportamentos podem ser entendidos como ações típicas de adolescentes com a sexualidade se desenvolvendo. Fica evidente a representação da sexualidade das PcD como um fenômeno descontrolado e assustador, provocando reações de temor nos educadores e profissionais mesmo em relação a comportamentos esperados pela faixa etária (GIAMI, 2004).

Para os educadores retratados nos artigos fica visível o entendimento moralista e a redução da sexualidade humana à prática genital, sendo que eles apresentam dificuldades ao trabalhar esses assuntos com seus alunos, transmitindo suas opiniões pessoais, com frequência pautadas no senso comum, ou demonstrando grande receio em abordar a temática. Os educadores relatam não terem formação específica para discutir as temáticas da área da sexualidade nem para propor programas de educação sexual.

Entende-se por educação sexual como a abordagem das temáticas relacionadas ao gênero e à sexualidade humana no ambiente escolar e familiar essencialmente, ocorrendo 
também nos demais espaços de convívio. Esses assuntos começaram a ser trabalhados na escola devido às preocupações de profissionais da saúde, sendo práticas para prevenção de gravidez na adolescência, doenças infecciosas e uso de substâncias ilegais através da divulgação de informações e conscientização de jovens. Atualmente as temáticas se expandiram, incluindo relações de gênero e orientação sexual. Mesmo sendo assuntos importantes e necessários, ainda se encontram dificuldades em discuti-los no ambiente escolar, seja por falta de formação ou por receios pessoais de educadores (RIBEIRO, 1990).

Atualmente, a educação sexual para alunos e alunas com deficiência matriculados na rede regular de ensino é amparada pela Lei de Diretrizes e Bases da Educação, de 1996, pelos Parâmetros Curriculares Nacionais, publicados em 1998, pelas Diretrizes Curriculares Nacionais da Educação Básica, de 2013, também se fazendo presente na Base Nacional Curricular Comum, com proposta de reformulação em 2018. Mesmo sendo uma parte da educação básica garantida por lei, encontram-se diversas dificuldades na prática da educação sexual na escola, tanto para alunos com quanto sem deficiência.

Voltando aos artigos analisados, as duas pesquisas que investigaram a sexualidade das PcD retratada pela mídia, seja nas capas de revista como em um livro autobiográfico analisado, obtiveram resultados similares aos encontrados a partir das representações de responsáveis e educadores. Os artigos analisados demonstram que as pessoas com deficiência são retratadas como seres sem sexualidade, não possuidoras de aspectos afetivos, sexuais e reprodutivos. No caso do livro autobiográfico, o apoio social e familiar foi fundamental para romper com os preconceitos voltados à vida afetiva.

Em relação aos artigos que investigam os discursos das próprias pessoas com deficiência sobre sua sexualidade, os resultados demonstraram uma nova gama de significados. As pessoas com deficiência física demonstram percepção positiva sobre sua própria sexualidade. Relatam ainda viver os tabus e preconceitos direcionados às suas expressões afetivo-sexuais, até carecendo de conhecimentos, mas tem a intenção de superá-los. Em casos de homens com paraplegia adquirida por acidentes ou episódios de violência, há um embate entre as ideias pré-estabelecidas de vigor, força e dominação sexual masculina e a situação física atual, o que causou sofrimento nos entrevistados, mas possibilitou a busca de maneiras alternativas de viver a sexualidade. Resultados similares foram encontrados por Oliveira (2016), o qual evidenciou a influência dos padrões de beleza e funcionalidade no modo como as pessoas com deficiência física se relacionam com seus corpos e vivem a sexualidade. 
Os homens que possuem deficiência física e são homossexuais enfrentam uma dupla carga de preconceitos, tanto na expressão sexual quanto nas relações sociais permeadas pela homofobia, demonstrando até indícios de desgaste psicológico e sofrimento psíquico.

No estudo que contou com mulheres e adolescentes cegas, elas relataram receber poucas orientações a respeito da sexualidade de suas famílias, tirando dúvidas e conversando abertamente com suas amigas. Ficaram presentes os questionamentos e a falta de informação sobre a sexualidade, além de discursos coercitivos e moralistas provenientes de familiares.

Nos artigos que contaram com pessoas com deficiência intelectual como seus participantes, estas relataram viver namoros e relações sob a vigilância de responsáveis e educadores. Elas vivem relações sexuais, mas geralmente escondidas e sem o uso de preservativos. Também há adultos que vivem uma eterna desconstrução de preconceitos para se caracterizar como adultos empoderados e com domínio da própria sexualidade.

As pessoas com DI, mesmo recebendo poucas orientações de responsáveis e educadores, encontram informações, corretas ou não, sobre sexo em diversos ambientes. Os participantes investigados entendem a sexualidade como uma característica importante de todos os seres humanos. No que tange a essa gama de artigos analisados, fica evidente a falta de informações fornecidas aos adolescentes com deficiência sobre a sua sexualidade, o que ocorre tanto por despreparo de docentes e dos profissionais da escola (SILVA; NETO, 2006) quanto por dificuldades em abordar o assunto no ambiente familiar. A fim de resolver tal problemática, se faz necessário programas de educação sexual no ambiente escolar que busquem orientar alunos, familiares e docentes.

Exemplos de programas e intervenções voltadas à educação sexual são encontrados em dois dos artigos analisados, os quais constam de duas pesquisa-ação que objetivaram discutir temáticas da sexualidade humana com pessoas com deficiência física e auditiva. Inicialmente foi relatado que os adultos participantes dos programas entendem a sexualidade humana apenas como o ato sexual e aos métodos contraceptivos e de prevenção de doenças. Ambos os públicos envolvidos foram participativos nos programas de intervenção, se beneficiando com as discussões e ampliando o conhecimento das temáticas relativas à sexualidade.

\section{Considerações finais}

A sexualidade das pessoas com deficiência é uma temática ainda pouco pesquisada, mas desperta interesse de alguns pesquisadores e pesquisadoras da atualidade. Temas como o 
ato sexual, nomenclatura das partes do corpo e a educação sexual se destacam no campo científico atual.

A partir dessa pesquisa constatou-se a grande incidência de estudos qualitativos, descritivos, que utilizam de entrevistas para investigar as concepções das pessoas com deficiência sobre sua sexualidade, além de seus responsáveis e educadores.

No caso das pessoas com deficiência intelectual, mesmo sendo o público mais abordado nas pesquisas, sua sexualidade ainda é relatada principalmente a partir da visão de outros. Esse grupo não é inteiramente legitimado a falar sobre a própria sexualidade, as outras pessoas ainda falam por elas, tanto seus professores/as quanto seus responsáveis. Já quem tem deficiência física é legitimado a falar sobre sua própria sexualidade. Em ambos os casos, os mitos da assexualidade das PcD se fazem visíveis, sendo que esses grupos vivem um eterno processo de desconstrução de preconceitos.

O lema de vários movimentos das pessoas com deficiência, "Nada de nós sem nós", ainda se manifesta de maneira ambígua nos estudos sobre a sexualidade: as PcD são convidadas a falar sobre si, seus próprios corpos e vivências, mas também são valorizados os discursos de terceiros.

Novas pesquisas na área da sexualidade e da deficiência se fazem necessárias, tanto para colher mais relatos das pessoas com deficiência quanto para investigar grupos pouco estudados, como as pessoas com deficiência visual e auditiva, e propor programas de orientação sexual com esse público. Espera-se que esse artigo tenha contribuído para as discussões da sexualidade das $\mathrm{PcD}$, questionado mitos e preconceitos e promovido reflexões.

AGRADECIMENTOS: Agradecemos ao Conselho Nacional de Desenvolvimento Científico e Tecnológico (CNPq) pelo financiamento desta pesquisa.

\section{REFERÊNCIAS}

AMADO, J. Manual de Investigação Qualitativa em Educação. Imprensa da Universidade de Coimbra/Coimbra University Press. 3ª edição. 2017.

AMARAL, L. A. Corpo desviante: olhar perplexo. Psicologia USP, v. 5, n. 1-2, p. 245-268, 1994.

AMARAL, L. A. Sobre crocodilos e avestruzes: falando de diferenças físicas, preconceitos e sua superação. In: Diferenças e preconceito na escola: alternativas teóricas e práticas, São Paulo. Summus. v. 5, p. 11-30; 1998. 
BRASIL. Estatuto da pessoa com deficiência. Lei Brasileira de Inclusão. Lei n ${ }^{\circ} 13.146$ de 6 de julho de 2015. Presidência da República, Brasília, 2015.

CARLOS, K. P. T.; SANTOS, J. V. O.; ARAUJO, L. F. Representações Sociais da velhice LGBT: estudo comparativo entre universitários de Direito, Pedagogia e Psicologia.

Psicogente, Barranquilla, v. 21, n. 40, p. 297-320, Dec. 2018.

DENARI, F. E. Adolescência, afetividade, sexualidade e deficiência intelectual: o direito ao ser/estar. Revista Ibero-Americana de Estudos em Educação, v. 5, n. 1, p. 44-52, 2010.

FOUCAULT, M. História da sexualidade I: A vontade de saber. Rio de Janeiro: Graal. Originalmente publicado em, 1976.

GESSER, M.; NUERNBERG, A. H. Psicologia, sexualidade e deficiência: Novas perspectivas em direitos humanos. Psicologia: ciência e profissão, v. 34, n. 4, p. 850-863, 2014.

GIAMI, A. O Anjo e a Fera: Sexualidade, Deficiência Mental, Instituição. Casa do Psicólogo, 2004.

GOFFMAN, E. Estigma: notas sobre a manipulação da identidade deteriorada. Rio de Janeiro: Coletivo Sabotagem, 1988.

GOMES, N.; PAIVA, A.; AMARAL, S.; CASTRO, B. A Diversidade na Educação Inclusiva e a Sexualidade da Pessoa com Deficiência Visual. InterSciencePlace, v. 12, n. 3, 2017.

HAYASHI, C. R. M. Apontamentos sobre a coleta de dados em estudos bibliométricos e cientométricos. Filosofia e Educação - Volume 5, Número 2. 2013.

LEITE JÚNIOR. J. Das maravilhas e prodígios sexuais: a pornografia "bizarra” como entretenimento. São Paulo: Annablume. 2006.

MAFFESOLI, M. Entre o Bem e o Mal. Compêndio de Subversão Pós-Moderna. Lisboa: Instituto Piaget, 2002.

MAZZOTTA, M. J. S.; D'ANTINO M. E. F. Inclusão social de pessoas com deficiências e necessidades especiais: cultura, educação e lazer. Saúde e Sociedade, v. 20, p. 377-389; 2011.

MIRANDA, A. C. S. Gênero/Sexo/Sexualidade: Representações e Práticas Elaboradas por Professoras/es da Educação Infantil na Rede Municipal de Ensino em Salvador. 166 f. Mestrado em Estudos Interdisciplinares sobre Mulheres, Gênero e Feminismo - Universidade Federal da Bahia. Faculdade de Filosofia e Ciências Humanas, 2014.

OLIVEIRA, E. L. "Pô, tô vivo, véio!": história de vida e sexualidade de pessoas com deficiências físicas. 2016. 191 f. Tese (Doutorado em Educação Especial) - Centro de Ciências Humanas, Universidade Federal de São Carlos, São Carlos, 2016. 
OLIVEIRA, E. L.; CARDOSO, D. C.; DENARI, F. E. O corpo humano como alimento para a sexualidade. DOXA: Revista Brasileira de Psicologia e Educação, v. 19, n. 1, p. 67-79, 2017.

RIBEIRO, M. Educação sexual além da informação. São Paulo: EPU. 1990.

RUAS, T. L.; PEREIRA, L. Como construir indicadores de Ciência, Tecnologia e Inovação utilizando Web of Science, Derwent World Patent Index, Bibexcel e Pajek?. Perspectivas em Ciência da Informação, v. 19, n. 3, p. 52-81, 2014.

SILVA, P. Y. F.; DIAS, J. C.; SANTOS, W. S.; KIAN, G. C.; RODRIGUES, L. B. A expressão da sexualidade em homens portadores de deficiência física adquirida. Revista Interfaces: Saúde, Humanas e Tecnologia, v. 2, n. 6, 2015.

SILVA, R. C. P. D.; NETO, J. M. Formação de professores e educadores para abordagem da educação sexual na escola: o que mostram as pesquisas. Ciência \& Educação (Bauru). v. 12, n. 2, p. 185-197. 2006.

SIMÕES, J. "A gente que está aqui é diferente": notas etnográficas sobre deficiência intelectual numa APAE do interior de São Paulo-BR. Teoria e Cultura, v. 11, n. 3, 2017.

VIEIRA, K. F. L.; COUTINHO, M. P. L.; SARAIVA, E. R. A. A sexualidade na velhice: representações sociais de idosos frequentadores de um grupo de convivência. Psicologia: Ciência e Profissão, v. 36, n. 1, p. 196-209, 2016.

\section{Como referenciar este artigo}

MENDES, Marlon Jose Gavlik. DENARI, Fátima Elisabeth. Deficiência e Sexualidade: Uma Análise Bibliométrica. Revista Ibero-Americana de Estudos em Educação, Araraquara, v. 14, n. esp. 2, p. 1357-1354, jul., 2019. E-ISSN: 1982-5587. DOI: 10.21723/riaee.v14iesp.2.12124

Submetido em: 31/01/2019

Revisões requeridas: 27/03/2019

Aprovado em: 28/04/2019

Publicado em: 26/06/2019 